\title{
SÍNDROME DA DELEÇÃO 2Q37.3-A PRIMEIRA DESCRIÇÃO DE ACHADOS ORAIS, RELATO DE CASO
}

\author{
2 2937.3 delection syndrome-The first description of oral phenotype,
}

a case report

\author{
(DCarolina Maschietto Pucinellia, (DRaquel Assed Bezerra Segatoa, (DPaulo Nelson-Filhoa, \\ Déa Assed Bezerra da Silvaa ${ }^{a}$ (DVivian Vicentin Massonia ${ }^{a}$ (DClara Marina Pereira Cavalcanti Silva ${ }^{a}$, \\ (D)Alexandra Mussolino de Queiroz ${ }^{\mathrm{a}}$
}

\section{RESUMO}

Introdução: A síndrome de deleção 2q37.3 é uma desordem causada pela microdeleção de uma sub-banda no cromossomo 2, cuja epidemiologia é de aproximadamente 150 casos no mundo, e a incidência de 1:10000. As características da síndrome são: atraso no desenvolvimento, dismorfia facial, anormalidades musculoesqueléticas e aumento ao risco de doenças congênitas. O objetivo deste relato de caso é apresentar, pela primeira vez na literatura, os achados clínicos orais e dentários associados à síndrome. Relato de caso: As principais características físicas da síndrome foram identificadas na paciente durante o exame físico: lábio superior fino, columela proeminente e dobras epicânticas. No exame intraoral, relatou-se as características odontológicas, que podem estar associadas à síndrome: acúmulo de cálculo dental, hipomineralização e hipoplasia, mordida cruzada, mordida aberta, agenesias, taurodontia e cisto dentígero. O tratamento dental consistiu na aplicação de técnicas de manejo de comportamento, instrução de higiene oral e de dieta, profilaxia, raspagem supragengival, aplicação tópica de flúor, além da extração do segundo molar decíduo inferior. Este é o primeiro relato de características orais da síndrome de deleção 2q37.3 dando importância às características observadas nesta paciente. Tais achados também serão úteis na caracterização da síndrome, que é extremamente rara, podendo contribuir para o diagnóstico clínico desses pacientes, além de subsidiar o tratamento odontológico de outros indivíduos. Conclusão: Apresentamos os achados clínicos orais como hipomineralização e hipoplasia, mordida cruzada e aberta, agenesia, taurodontia e cisto dentígero presentes na paciente com a síndrome e sugerimos que o gene envolvido ou sua deleção possam ser responsáveis por tais achados.
Palavras-chave: Doenças raras. Síndrome. Deleção de genes. Saúde bucal. Relatos de casos.

\section{ABSTRACT}

Introduction: The $2 \mathrm{q} 37.3$ deletion syndrome is a disorder caused by the microdeletion of a subband on chromosome 2, whose epidemiology is approximately 150 cases worldwide, and the prevalence of 1:10000. Its characteristics are developmental delay, facial dysmorphia, musculoskeletal abnormalities, and increased risk of congenital diseases. The purpose is to present, for the first time in the literature, the oral and dental clinical findings associated with the syndrome. Case report: The main physical characteristics of the syndrome were identified during the physical examination: thin upper lip, prominent columella, and epicanthic folds. In the intraoral examination, dental characteristics were reported, which may be associated with the syndrome: accumulation of dental calculus, hypomineralization and hypoplasia, crossbite, open bite, agenesis, taurodontism, and dentigerous cyst. The dental treatment consisted of the application of behavior management techniques, oral hygiene and diet instruction, prophylaxis, supragingival scraping, topical fluoride application, and extraction of the lower second molar. This is the first report of oral characteristics of the 2 q37.3 deletion syndrome, giving importance to the characteristics observed in this patient. Such findings will be useful in the characterization of the syndrome, which is extremely rare, and may contribute to the clinical diagnosis of these patients, in addition to subsidizing the dental treatment of other individuals. Conclusion: We present oral clinical findings such as hypomineralization and hypoplasia, crossed and an open bite, agenesis, taurodontism, and dentigerous cyst

${ }^{a}$ Universidade de São Paulo, Departamento de Clínica Infantil, Faculdade de Odontologia de Ribeirão Preto, Ribeirão Preto, SP, Brasil.

Autora de correspondência: Vivian Vicentin Massoni - E-mail: vivian.massoni@usp.br

Data de envio: 15/09/2020 | Data de aceite: 30/11/2020 
present in the patient with the syndrome and we suggest that the involved gene or its deletion may be responsible for such findings.

Keywords: Rare diseases. Syndrome. Gene deletion. Oral health. Case reports.

\section{INTRODUÇÃO}

A síndrome de deleção cromossômica 2q37.3 (OMIM: 600430 e ORPHA: 1001), é uma microdeleção da sub-banda 3 localizada no cromossomo 2 causada pela haploinsuficiência das instruções genéticas incluídas nesta deleção. Reportada como uma doença rara, a epidemiologia até o ano de 2020, é de aproximadamente 150 casos no mundo, sendo o sexo feminino $60 \%$ mais afetado ${ }^{1}$. A prevalência ainda é desconhecida e a incidência é de 1:10000 ${ }^{1,2}$. Foi levantada a hipótese de que o principal gene, responsável principalmente pela maioria do fenótipo clínico desses pacientes, seja o gene histona desacetilase 4 (HDAC4), que participa da regulação do desenvolvimento ósseo e muscular ${ }^{3,4}$.

A apresentação clínica da síndrome é variável e pode ser caracterizada por desenvolvimento psicomotor moderado a significativamente atrasado, além de deficiência de comunicação e interação social, hiperatividade, agressividade intermitente, déficit na atenção, bem como características de autismo em aproximadamente um terço dos pacientes. Outras características são os achados esqueléticos como braquimesofalangia, baixa estatura e/ou escoliose, obesidade, hipotonia, hipermobilidade, convulsões, cardiopatia congênita, hérnia umbilical, anormalidades gastrointestinais e, raramente, tumor de Wilms ${ }^{5-9}$. Por tais características que podem dificultar a colaboração durante o atendimento e sua qualidade de vida, o paciente precisa de maiores cuidados, estes relacionados ao seu comportamento e a sua saúde, requerendo um acompanhamento multidisciplinar com equipe médica, odontológica, nutricional, fonoaudiólogos, entre outros ${ }^{1}$.

As características faciais dos pacientes são frequentemente descritas como sobrancelhas esparsas e arqueadas, testa proeminente, olhos profundos, fissuras palpebrais inclinadas para cima, lábio superior fino, dobras epicânticas e columelas proeminentes ${ }^{6-10}$.

Para realizar o diagnóstico dessa síndrome, a observação da presença de características fenotípicas relacionadas, como atraso no desenvolvimento, malformações e dimorfismo facial, baseiam a hipótese diagnóstica e levantam a suspeita clínica inicial ${ }^{5}$. Assim, para obter o diagnóstico, é necessário acompanhamento genético, podendo ser realizadas a análise citogenética e a caracterização molecular do paciente. Também é possível fazê-lo no pré-natal, por meio do aconselhamento genético ${ }^{1}$. É importante destacar que o diagnóstico precoce desta síndrome permite acompanhar o neurodesenvolvimento e realizar intervenções adequadas no manejo desses problemas cognitivos e comportamentais. Já que o prognóstico e a expectativa de vida são influenciados pela presença de malformações congênitas ${ }^{1}$. Além disso, possibilita avaliações periódicas de, por exemplo, cistos renais e tumor de Wilms, podendo amenizar algumas das consequências da síndrome. Assim, o reconhecimento pelo Cirurgião-Dentista das características físicas e sua associação com possíveis achados clínicos orais, como os que serão relatados neste artigo, auxiliarão no diagnóstico precoce ${ }^{2,5}$.

Ainda sobre o diagnóstico, é realizado o rastreamento genético por meio de análises citogenéticas e genética molecular, a partir de técnicas de hibridização genômica comparativa baseada em microarray (Array CGH), PCR quantitativo em tempo real (qPCR) e hibridização fluorescente in situ (FISH) as quais permitem a visualização da deleção no cromossomo 2q37.3 ${ }^{11}$. O Hospital das Clínicas da Faculdade de Medicina de Ribeirão Preto da USP é um centro, com referência nacional, que estuda e elucida diagnósticos difíceis de doenças raras, promovendo um melhor cuidado desses pacientes por meio da informação e aconselhamento aos mesmos, como também familiares, profissionais e público em geral ${ }^{12}$. Incentivos financeiros para 
ações de promoção, prevenção, diagnóstico, tratamento multiprofissional e cuidados paliativos foram instituídos através da portaria n. ${ }^{\circ} 199$, que trata da Política Nacional de Atenção Integral às Pessoas com Doenças Raras, no âmbito do Sistema Único de Saúde (SUS) ${ }^{13}$. No entanto a sua implementação não foi totalmente efetiva desde a sua criação, dificultando a qualidade de vida dos pacientes com necessidades especiais.

Este é o primeiro relato dos achados orais e dentários de um paciente com síndrome de deleção do 2q37.3, além da descrição do tratamento odontológico desse paciente, destacando a contribuição deste relato para a prática clínica dos profissionais envolvidos.

\section{RELATO DE CASO}

Paciente de 11 anos, com diagnóstico de síndrome da deleção 2q37.3, compareceu ao serviço especializado- Clínica de Pacientes Especiais (CAOPE) da Faculdade de odontologia de Ribeirão Preto (FORP-USP) (Figura 1A). A paciente era a segunda filha de pais não consanguíneos. Ela nasceu com 31 semanas de gestação com parâmetros neonatais normais. $\mathrm{Na}$ história médica a mãe relatou que a filha apresentava o diagnóstico da síndrome da deleção 2q37.3, por isso possuía atraso no desenvolvimento e perda de audição. Na família não havia nenhuma história anterior dessa síndrome, e os pais possuíam cariótipo normal, não eram portadores de outras síndromes. A mãe observou que a filha aos 4 anos tinha dificuldade em escutar, não reagia quando era chamada, e então decidiu levá-la ao médico, o qual encaminhou a paciente para uma avaliação genética com a suspeita que essa perda auditiva, juntamente com as características físicas, poderiam estar associadas a uma anomalia congênita. A avaliação genética no Hospital das Clínicas da Faculdade de Medicina de Ribeirão Preto da USP confirmou o diagnóstico da síndrome de deleção 2q37.3.

Foi relatado durante a anamnese, pela responsável pela paciente, os medicamentos que a mesma fazia uso por meio da receita médica e também sua história psicossocial, e que a paciente estudava e possuía um comportamento sociável, mas também apresentava déficit de atenção, distúrbio de hiperatividade, dificuldades de aprendizagem, associadas ao atraso no desenvolvimento psicomotor. Passava a maior parte do tempo com a mãe e em alguns momentos apresentava um comportamento mais agressivo, auto lesivo, principalmente quando se chateava. Não apresentava hábitos parafuncionais, além de já ter ido ao dentista anteriormente, onde realizou apenas remoção de cárie. Diariamente, a paciente é medicada com Imipramina (Imipramina - Aspen Pharma 100mg/dia) uma vez ao dia e Risperidona (Risperidona - Eurofarma $0,5 \mathrm{mg} / \mathrm{dia}$ ) dose única diária pela manhã ou à noite, na tentativa de minimizar o comportamento agressivo e auto prejudicial. Após 8 meses de uso desses medicamentos, a paciente ganhou quase $10 \mathrm{~kg}$ de peso (Figura $1 \mathrm{~B}$ e C), o que não influenciou na sua saúde bucal. 


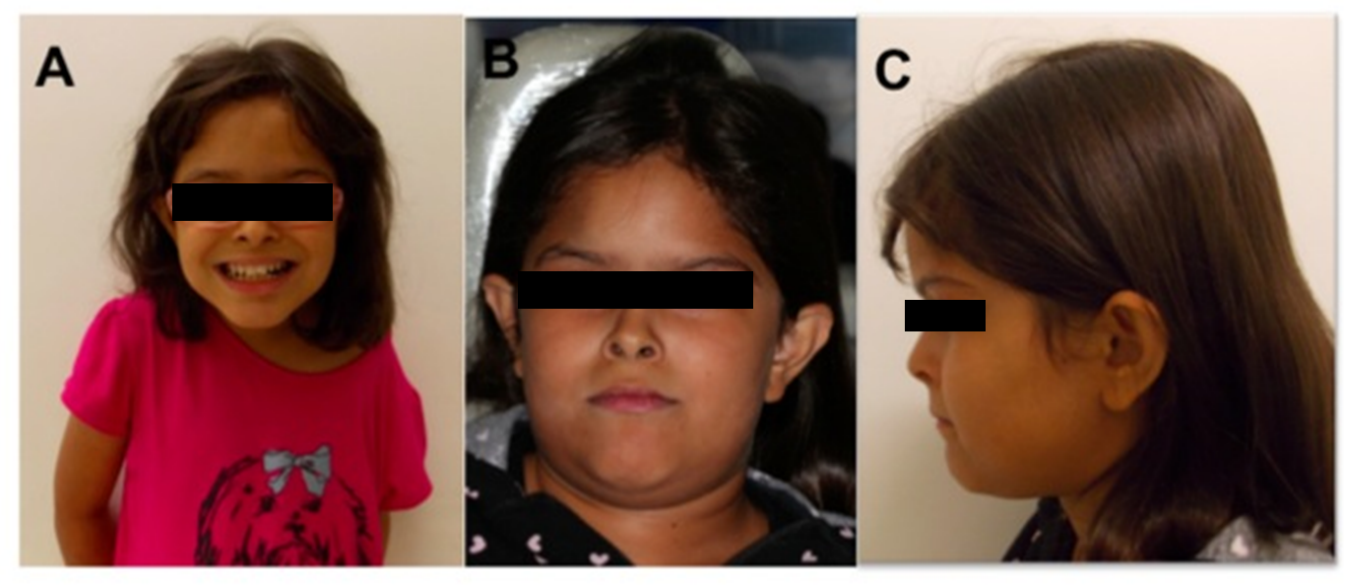

Figura 1: Características faciais de paciente com síndrome de deleção 2q37.3 como lábio superior fino, columela proeminente, pregas epicânticas, orelhas de implantação baixa com proeminência auricu$\operatorname{lar}(\mathrm{A}, \mathrm{B}$ e C). Note em (A) que a paciente iniciou o tratamento com Risperidona e em (B) e (C) após 8 meses de tratamento com esse medicamento.

O tratamento da paciente consistia na medicação, acompanhamento por sua médica pediatra e por um geneticista, o qual após os exames, diagnosticou a síndrome sem maiores dificuldades e continua acompanhando a paciente. Quanto aos cuidados especiais que a paciente requer, a responsável era dona de casa e conseguia acompanhá-la em todas as consultas e atividades necessárias. Porém, a maior dificuldade era o deslocamento, pois a paciente residia a uma distância de $89 \mathrm{~km}$ da cidade em que comparecia para os acompanhamentos médicos e consultas odontológicas. Tal distância demandava que ambas, paciente e acompanhante saíssem de casa muito cedo para se deslocar por meio do transporte oferecido pela prefeitura, e voltavam para casa bem tarde também por conta desse transporte, o qual precisava esperar o atendimento de todos os pacientes da cidade para retornar.

Inicialmente, a paciente foi atendida por uma estudante de odontologia da CAOPE, supervisionada por um professor, e durante a primeira consulta, ambos realizaram os exames físicos, intraorais e radiográficos. Durante o exame físico, registrou-se baixa estatura (abaixo de P5), hipotonia muscular, hipertricose, quarto dedo menor nas mãos e nos pés, hérnia umbilical (Figura 2), orelhas baixas e proeminentes (Figura 1C). Consistentemente com as características faciais relatadas dessa síndrome, a paciente apresenta lábio superior fino, columela proeminente e pregas epicânticas (Figura 1). A Tabela 1 descreve as características da síndrome 2q37.3 descritas na literatura em comparação com as características presentes ou não no paciente relatado. 

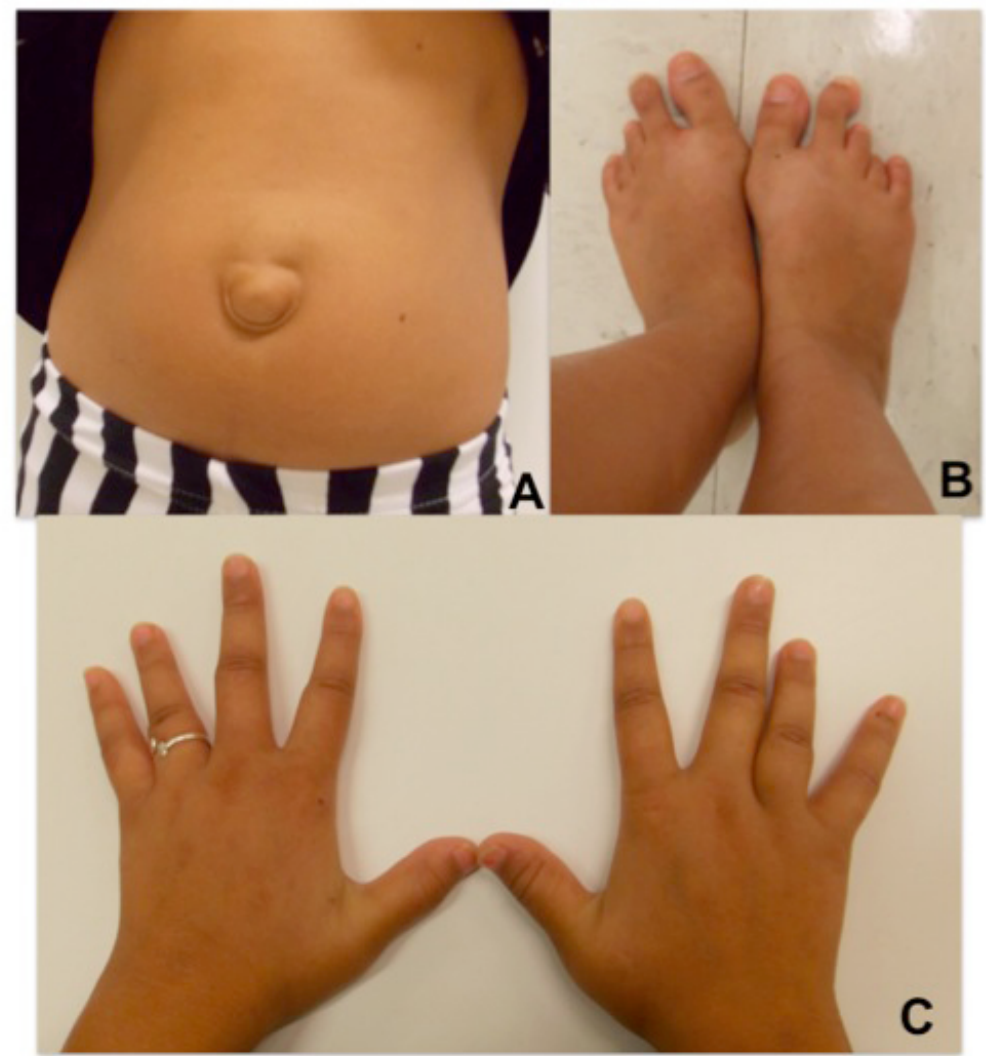

Figura 2: Características clínicas da síndrome da deleção 2q37.3 como hérnia umbilical (A) e encurtamento simétrico do $3 .^{\circ}$ e $4 .^{\circ}$ dedos (B) e encurtamento simétrico dos $4 .^{\circ \text { s }}$ dedos e metacarpos, além da falange distal do $1 .^{\circ}$ dedo.

Tabela 1: Características da síndrome 2937.3 descritas na literatura em comparação com as características presentes ou não no paciente relatado.

\begin{tabular}{llll}
\hline $\begin{array}{l}\text { Características da síndrome } \\
\text { descritas na literatura }\end{array}$ & $\begin{array}{l}\text { Características } \\
\text { presentes no } \\
\text { paciente relatado }\end{array}$ & $\begin{array}{l}\text { Características } \\
\text { que não estão } \\
\text { presentes no } \\
\text { paciente relatado }\end{array}$ & $\begin{array}{l}\text { Informação } \\
\text { não reportada }\end{array}$ \\
\hline Baixa estatura & $\times$ & $\times$ \\
Obesidade & $X$ & \\
Rosto redondo & $\times$ & \\
Hipoplasia do meio da face & $\times$ & \\
$\begin{array}{l}\text { Perda de audição neurosen- } \\
\text { sorial }\end{array}$ & $\times$ & \\
Olhos profundos & $\times$ & \\
Sobrancelhas bem arqueadas & & \\
\hline
\end{tabular}




\begin{tabular}{|c|c|c|c|}
\hline $\begin{array}{l}\text { Características da síndrome } \\
\text { descritas na literatura }\end{array}$ & $\begin{array}{l}\text { Características } \\
\text { presentes no } \\
\text { paciente relatado }\end{array}$ & $\begin{array}{l}\text { Características } \\
\text { que não estão } \\
\text { presentes no } \\
\text { paciente relatado }\end{array}$ & $\begin{array}{l}\text { Informação } \\
\text { não reportada }\end{array}$ \\
\hline Nariz largo & $x$ & & \\
\hline Nariz arrebitado & $x$ & & \\
\hline Braquidactilia & $x$ & & \\
\hline Eczema & & $x$ & \\
\hline Atraso de desenvolvimento & $x$ & & \\
\hline Retardo mental & $x$ & & \\
\hline Distúrbios de sono & & $x$ & \\
\hline Dispraxias motoras & & $x$ & \\
\hline Convulsões & & $x$ & \\
\hline Hiporreflexia & & $x$ & \\
\hline Insensibilidade à dor & & $x$ & \\
\hline Comportamento autolesivo & $x$ & & \\
\hline Comportamento agressivo & $x$ & & \\
\hline Características de autismo & & & $x$ \\
\hline Hiperatividade & $x$ & & \\
\hline Comportamentos repetitivos & & $x$ & \\
\hline
\end{tabular}

Durante a primeira consulta, foi realizada a anamnese, exame intra oral e exame radiográfico - radiografia panorâmica, além do contato com o médico geneticista do HC visando alinhar os planos de tratamento da paciente.

O exame intra oral mostrou acúmulo de cálculo dentário principalmente nos incisivos inferiores, dentes com hipomineralização do esmalte e hipoplasia (ambos os primeiros molares superiores, ambos os primeiros molares inferiores, ambos os incisivos centrais superiores, canino superior esquerdo, incisivo lateral inferior esquerdo e incisivo central inferior esquerdo), arco maxilar atrésico, mordida cruzada e mordida profunda (Figura 3). 


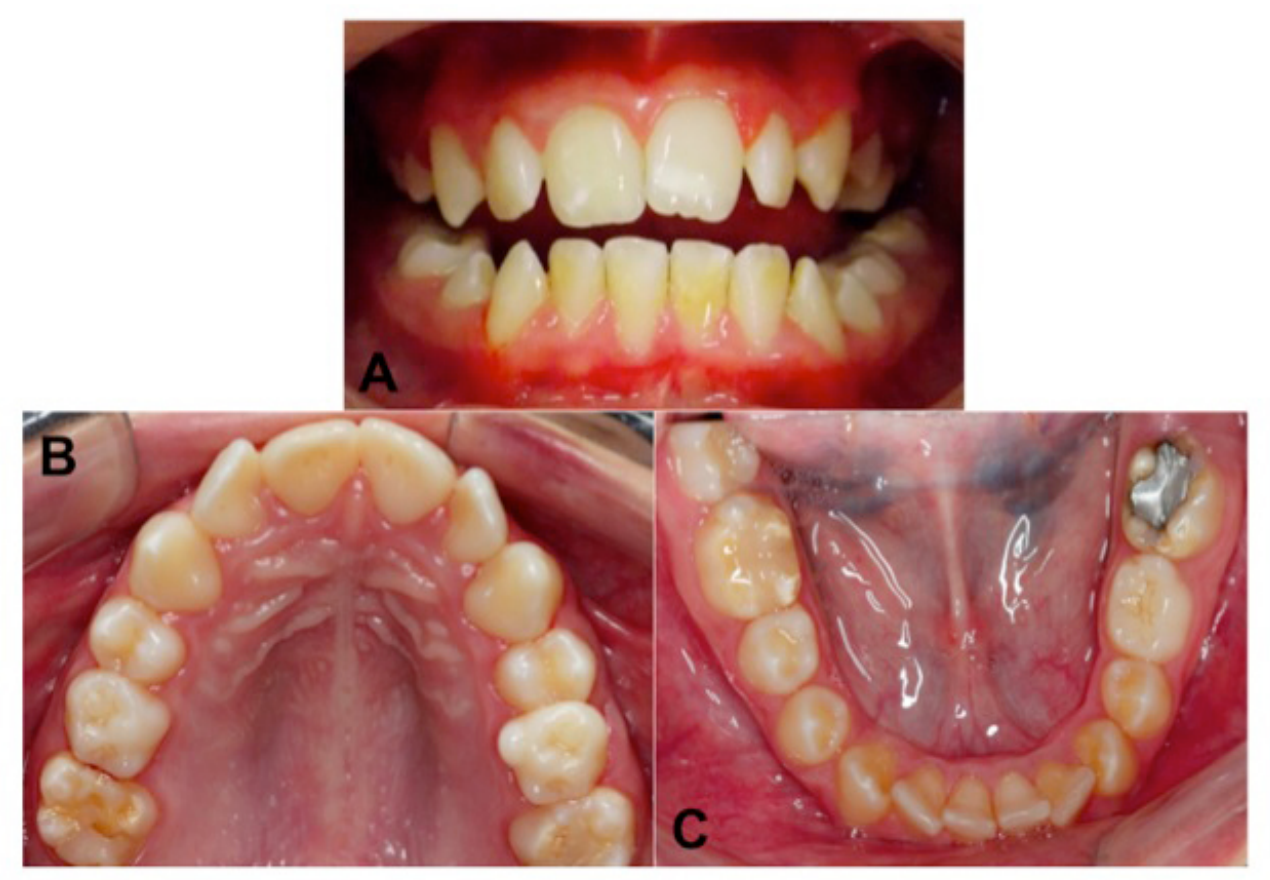

Figura 3: Visão intraoral da paciente com Síndrome da deleção 2q37.3 mostrando acúmulo de cálculo dentário nos incisivos inferiores (A) e cíngulo proeminente (nos incisivos centrais e laterias superiores), arco maxilar atrésico (B). Presença de hipoplasia de esmalte (nos primeiros molares superiores e inferiores, nos incisivos centrais superiores, no canino superior esquerdo, incisivo lateral e central inferiores esquerdos) (C).

Durante o exame radiográfico, foi observada agenesia dentária múltipla (todos os terceiros molares, segundo pré-molar superior esquerdo e segundo pré-molar inferior esquerdo). Além disso, havia retenção prolongada do segundo molar decíduo inferior direito com presença de cisto dentígero na coroa do sucessor permanente (segundo pré-molar) e cíngulo proeminente nos incisivos centrais superiores e nos incisivos laterais superiores. Observou-se taurodontismo nos dois primeiros molares superiores (Figura 4).

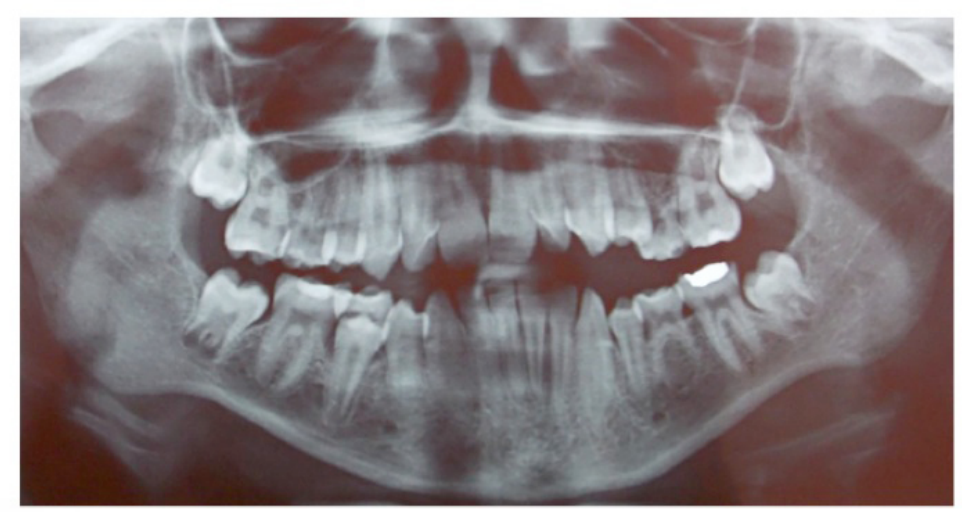

Figura 4: Radiografia panorâmica mostrando agenesia dentária múltipla (terceiros molares, segundo pré-molar superior e inferior esquerdos), retenção prolongada do segundo molar decíduo direito com presença de cisto dentígero, cíngulo proeminente (nos incisivos centrais e laterais superiores) e taurodontismo (nos primeiros molares superiores). 
A segunda consulta consistiu na elaboração do plano de tratamento, de acordo com sua classificação de risco e atividade de cárie, apresentando médio e baixa respectivamente, e com a divisão dos procedimentos em cinco sessões clínicas. Tal plano de tratamento incluiu na terceira consulta, a realização de escovação supervisionada e instrução de higiene oral, para a paciente e os pais, visto que a mãe relatou dificuldade na escovação da filha, visando a diminuição da formação do cálculo dental encontrada clinicamente. Também foram instruídos quanto a dieta, pois ela apresentava uma dieta rica em açúcar, com lanches frequentes, e foi feita a aplicação de técnicas básicas de comportamento gerencial (com resultados substanciais). Ademais, na quarta consulta, foi realizada a profilaxia dentária, raspagem supragengival e aplicação tópica de fluoreto de sódio (Flugel 2\% Gel - DFL). Após as consultas de manejo do comportamento, na quinta consulta, foi realizado um procedimento mais invasivo, a extração do segundo molar decíduo inferior direito devido a retenção prolongada do segundo molar decíduo direito com presença de cisto dentígero.

A paciente retornou para acompanhamento após 5, 8 e 11 meses para realizar profilaxia e aplicação tópica de flúor, além de orientações preventivas.

\section{DIsCUSSÃo}

Este é o primeiro relato observacional das características orais da síndrome de deleção 2q37.3, dando importância às características encontradas nesta paciente. O trabalho tem como ponto forte ser o primeiro relato das características orais dessa síndrome, que é muito rara e pouco encontrada na literatura. Ao mesmo tempo, essa escassez de informações dificulta a associação dos achados com a deleção 2q37.3, os quais também serão úteis na sua caracterização e podem contribuir para o diagnóstico clínico desses pacientes, pois quando encontrados pelo cirurgião-dentista sugerem o encaminhamento e o rastreamento da síndrome, além de apoiar e guiar o tratamento odontológico de outros indivíduos. Pois apesar dos pacientes com necessidades especiais terem acesso à atenção em saúde bucal, continuam com necessidades odontológicas não atendidas mesmo sendo “assistidos” por um profissional, visto que não se sentem capacitados.

Neste relato clínico, foi descrito que a paciente apresentava vários dentes com hipomineralização do esmalte e/ou hipoplasia. Vale ressaltar que a hipomineralização do esmalte foi observada principalmente no terço médio. Essa área não é característica das lesões da mancha branca por cárie, mas de defeitos no esmalte dental, que ocorrem durante o período de deposição e mineralização da matriz. Entretanto, essa estrutura alterada, mais porosa e retentiva, pode levar à perda do esmalte dentário e à integridade da superfície dentária, aumentando o risco de aderência bacteriana e sua colonização ${ }^{8}$.

Essa hipomineralização pode ser causada por distúrbios que ocorrem no estágio de calcificação ou maturação ${ }^{14}$. Apesar de alguns autores ${ }^{15,16}$ relacionarem a medicação como fator de risco para hipomineralização molar incisivo (HMI), no entanto, existem evidências insuficientes para verificar a existência de tais fatores causais ${ }^{17}$. Essa hipomineralização é o resultado de fatores ambientais que atuam sistematicamente afetando o esmalte em desenvolvimento, enquanto uma predisposição genética subjacente não deve ser excluída ${ }^{18}$.

São encontradas malformações na síndrome 2q37.3, e na cavidade bucal foi observado agenesias dentárias, forma mais comum de anomalia de desenvolvimento em humanos. Geralmente está associado a outras doenças genéticas, fazendo parte de uma síndrome ou sendo um traço familiar ${ }^{19}$. É genética e fenotipicamente uma condição heterogênea, causada por vários genes defeituosos independentes ${ }^{20}$. No presente relato de caso, foi observada agenesia dentária múltipla (todos os terceiros molares, segundo pré-molar superior esquerdo e segundo pré-molar inferior esquerdo). 
Também foi observado taurodontismo nos dois primeiros molares superiores. Sabe-se que anomalias dentárias, como o taurodontismo, são defeitos formativos causados por desordens genéticas durante a morfogênese do dente. É comum atribuir a etiologia do taurodontismo ao fracasso da invaginação do epitélio da bainha radicular suficientemente cedo para formar o cynodont ${ }^{21}$ (dentes que apresentam a câmara pulpar relativamente pequena, com inserção baixa na coroa e constrição na junção amelocementária) ${ }^{22}$. O taurodontismo aparece frequentemente como uma anomalia isolada, mas também tem sido associado a várias síndromes e anomalias do desenvolvimento ${ }^{23}$.

A hipotonia oromotora presente na síndrome, pode resultar em um palato arqueado e no aparecimento de uma mordida cruzada, como foi relatada na paciente ${ }^{5}$. Outro achado importante é que pacientes que fazem uso da medicação Imipramina têm como reação adversa muito comum, distúrbios no metabolismo e nutrição, que culminam em aumento de peso. Esse ganho de peso pode estar relacionado com o aparecimento de doenças no futuro, como a obesidade e doenças cardiovasculares ${ }^{24,25}$. Além disso, o uso desse medicamento pode potencializar os efeitos cardiovasculares da adrenalina, noradrenalina, isoprenalina, efedrina e fenilefrina ${ }^{24}$, componentes frequentemente presentes nos anestésicos locais utilizados na prática clínica odontológica, sinalizando assim, a necessidade de cuidado por parte dos cirurgiões dentistas para com cirurgias extensas, que exijam o uso de doses maiores destes anestésicos locais, em pacientes que fazem uso dessa medicação.

O HDAC4 pode ser um dos principais mediadores a jusante do receptor autócrino/ parácrino, sinalizando em progenitores mesenquimais dentários essenciais para a formação da raiz do dente ${ }^{26}$. A mutação nesse gene e/ou sua exclusão poderia explicar os achados de agenesia dentária oral e/ou taurodontismo. Além disso, a síndrome de microdeleção 2q37 é uma síndrome gênica contígua associada à deleção ou mutação heterozigótica no gene HDAC4 no cromossomo 2q37.3 $3^{27,28}$. Apesar desses achados da literatura científica, no caso específico deste artigo, apenas sugerimos que esse gene e essa deleção possam ser responsáveis pelos achados orais presentes neste paciente.

Saber diagnosticar esses pacientes permite o acompanhamento e a realização de intervenções adequadas, fornecendo uma melhor qualidade de vida. O Cirurgião-Dentista atua no tratamento multidisciplinar, incluindo uma avaliação abrangente dos critérios clínicos mais importantes.

\section{CONCLUSÃo}

Apresentamos os achados clínicos orais como acúmulo de cálculo dental, hipomineralização e hipoplasia, mordida cruzada e aberta, agenesia, taurodontia e cisto dentígero presentes na paciente com deleção do 2q37.7 e sugerimos que o gene envolvido nessa síndrome ou sua deleção possam ser responsáveis por esses achados orais, sendo necessários mais estudos para elucidar tal possível associação.

\section{CONFLITO DE INTERESSES}

Os autores declaram não haver conflito de interesses. 


\section{REFERÊNCIAS}

1. Doco-Fenzy M. Síndrome da microdeleção 2q37: ORPHA:1001 [Internet]. Brasil: Martine DOCO-FENZY; 2008 [revised 2008 Aug 1; cited 2020 Oct 28]. Available from: https://www.orpha.net/consor/cgi-bin/Disease_Search. php?lng=PT\&data_id=1313\&Disease_Disease_Search_diseaseGroup=2q37-3\&Disease_Disease_Search_diseaseType=Pat\&Grupo\%20de\%2Odoen\%E7as\%20relacionadas=S-ndrome-da-microdelec-o-2q37\&title=S\%EDndrome\%20da\%20microdele\%E7\%E30\%202q37\&search=Disease_Search_Simple.

2. Doherty ES, Lacbawan FL. 2937 Microdeletion Syndrome-Retired chapter, for historical reference only. In: Adam MP, Ardinger HH, Pagon RA, Wallace SE, Bean JH, Stephens K, et al. editors. GeneReviews ${ }^{\circledR}$ [Internet]. Seattle (WA): University of Washington; 2007 May 3 [updated 2013 ]an 31; cited 2020 Dez 16]. Available from: https:// pubmed.ncbi.nlm.nih.gov/20301337/.

3. Morris B, Etoubleau C, Bourthoumieu S, Reynaud-Perrine S, Laroche C, Lebbar A, et al. Dose dependent expression of HDAC4 causes variable expressivity in a novel inherited case of brachydactyly mental retardation syndrome. Am ] Med Genet A. 2012 Aug;158A(8):2015-20.

4. Williams SR, Aldred MA, Der Kaloustian VM, Halal F, Gowans G, McLeod DR, et al. Haploinsufficiency of HDAC4 causes brachydactyly mental retardation syndrome, with brachydactyly type $\mathrm{E}$, developmental delays, and behavioral problems. Am ] Hum Genet. 2010 Aug;87(2):219-28.

5. Falk RE, Casas KA. Chromosome 2937 deletion: clinical and molecular aspects. Am ] Med Genet C Semin Med Genet. 2007 Nov; 145C(4):357-71.

6. Phelan MC, Rogers RC, Clarkson KB, Bowyer FP, Levine MA, Estabrooks LL, et al. Albright hereditary osteodystrophy and del(2) (937.3) in four unrelated individuals. Am ] Med Genet. 1995 ]ul;58(1):1-7.

7. Wilson LC, Leverton K, Oude Luttikhuis ME, Oley CA, Flint ], Wolstenholme ], et al. Brachydactyly and mental retardation: an Albright hereditary osteodystrophy-like syndrome localized to 2q37. Am ] Hum Genet. 1995 Feb;56(2):400-7.

8. Aldred MA, Sanford RO, Thomas NS, Barrow MA, Wilson LC, Brueton LA, et al. Molecular analysis of 20 patients with 2q37.3 monosomy: definition of minimum deletion intervals for key phenotypes. J Med Genet. 2004 Jun;41(6):433-9.

9. Drake KM, Ruteshouser EC, Natrajan R, Harbor P, Wegert ], Gessler M, et al. Loss of heterozygosity at 2937 in sporadic Wilms' tumor: putative role for miR-562. Clin Cancer Res. 2009 Apr;15(19):5985-92.

10. Zhou Y, Yang JY, Zhi QH, Tao Y, Qiu RM, Lin HC. Factors associated with colonization of Streptococcus mutans in 8- to 32-month-old children: a cohort study. Aust Dent ]. 2013 Dec;58(4):507-13.

11. Spielmann M, Marx S, Barbi G, Flöttmann R, Kehrer-Sawatzki H, König R, et al. Femoral facial syndrome associated with a de novo complex chromosome 2937 rearrangement. Am ] Med Genet A. 2016 May;170A(5):1202-7.

12. Biocel: Departamento de Biologia Celular e Molecular e Bioagentes Patogênicos Faculdade de Medicina de Ribeirão Preto-USP [Internet]. Ribeirão Preto: ]ornal USP; 2019. HC é referência nacional no estudo de doenças raras: Departamento de Biologia Celular e Molecular e Bioagentes Patogênicos; revised 2019 ]an 1 [cited 2020 Oct 28]. Available from: http://rbp.fmrp.usp.br/hc-e-referencia-nacional-no-estudo-de-doencas-raras/.

13. Brasil. Ministério da saúde. Secretaria de atenção à saúde. Departamento de atenção especializada e temática. Coordenação geral de média e alta complexidade. Portaria gm/ms nº 199 de 30/01/2014-diretrizes para atenção integral às pessoas com doenças raras no sistema único de saúde. Brasília: Ministério da saúde; 2014.

14. Gawenis LR, Spencer P, Hillman LS, Harline MC, Morris ]S, Clarke LL. Mineral content of calcified tissues in cystic fibrosis mice. Biol Trace Elem Res. 2001 Oct;83(1):69-81.

15. Wuollet E, Laisi S, Salmela E, Ess A, Alaluusua S. Molar-incisor hypomineralization and the association with childhood illnesses and antibiotics in a group of Finnish children. Acta Odontol Scand. 2016 Jul;74(5):416-22.

16. Serna C, Vicente A, Finke C, Ortiz AJ. Drugs related to the etiology of molar incisor hypomineralization: a systematic review. J Am Dent Assoc. 2016 Feb;147(2):120-30.

17. Alaluusua S. Aetiology of molar-incisor hypomineralisation: a systematic review. Eur Arch Paediatr Dent. 2010 Apr;11(2):53-8.

18. Ferrazzano GF, Orlando S, Sangianantoni G, Cantile T, Ingenito A. Dental and periodontal health status in children affected by cystic fibrosis in a southern Italian region. Eur ] Paediatr Dent. 2009 Jun;10(2):65-8.

19. Nasman M, Forsberg CM, Dahllof G. Long-term dental development in children after treatment for malignant disease. Eur ] Orthod. 1997 Apr;19:151-9.

20. Chhabra N, Goswami M, Chhabra A. Genetic basis of dental agenesis-molecular genetics patterning clinical dentistry. Med Oral Patol Oral Cir Bucal. 2014 Mar;19(2):e112-9.

21. Witkop ]r. C]. Manifestations of genetic diseases in the human pulp. Oral Surg Oral Med Oral Pathol. 1971 Aug;32:278-316.

22. Kosinski RW, Chaiyawat Y, Rosenberg L. Localized deficient root development associated with taurodontism: case report. Pediatr Dent. 1999;21(3):213-5. 
23. Dineshshankar ], Sivakumar M, Balasubramanium AM, Kesavan G, Karthikeyan M, Prasad VS. Taurodontism. ] Pharm Bioallied Sci. 2014 Jul;6(Suppl 1):S13-5.

24. Imipramina. Bula do medicamento Tofranil ${ }^{\circledR}$. [acesso 2020 out 25]. Disponível em: http://www.anvisa.gov.br/ datavisa/fila_bula/frmVisualizarBula.asp.

25. Koliaki C, Liatis S, Kokkinos A. Obesity and cardiovascular disease: revisiting an old relationship. Metabolism. 2019 Mar 92:98-107.

26. Ono W, Sakagami N, Nishimori S, Ono N, Kronenberg HM. Parathyroid hormone receptor signalling in osterix-expressing mesenchymal progenitors is essential for tooth root formation. Nat Commun. 2016 Apr 12;7:11277.

27. Morris B, Etoubleau C, Bourthoumieu S, Reynaud-Perrine S, Laroche C, Lebbar A, et al. Dose dependent expression of HDAC4 causes variable expressivity in a novel inherited case of brachydactyly mental retardation syndrome. Am $]$ Med Genet A. 2012 Aug;158A(8):2015-20.

28. Williams SR, Aldred MA, Der Kaloustian VM, Halal F, Gowans G, McLeod DR, et al. Haploinsufficiency of HDAC4 causes brachydactyly mental retardation syndrome, with brachydactyly type $\mathrm{E}$, developmental delays, and behavioral problems. Am J Hum Genet. 2010 Aug;87(2):219-28. doi: 10.1016/j.ajhg.2010.07.011. 